\title{
MATERIALISMO ELECTORAL
}

\author{
Pablo Huerga Melcón \\ Universidad de Oviedo
}

https://doi.org/10.33676/EMUI_nomads.57.01

\begin{abstract}
Resumen: Se propone un análisis desde las coordenadas del Materialismo Filosófico de Gustavo Bueno del contexto político del debate electoral. Proponemos una reinterpretación de la idea de sujeto político, de la idea de Estado y de la idea de soberanía nacional. Además se propone un ensayo de estudio de las relaciones entre las ideas de Libertad, Igualdad y Fraternidad, en su contexto político, desde la perspectiva del espacio axiológico compuesto por los ejes de la ética, la moral y la política. Finalmente, se procede a una crítica sistemática de la idea de Estado tal y como venía proponiéndola el enfoque marxista.
\end{abstract}

\section{Electoral Materialism}

Abstract: We propose an analysis from the coordinates of Gustavo Bueno's Philosophical Materialism from the political context of the electoral debate. We propose a reinterpretation of the idea of political subject, of the idea of State and of the idea of national sovereignty. It also proposes an essay to study the relationships between the ideas of Freedom, Equality and Fraternity, in its political context, from the perspective of the axiological space composed of the axes of ethics, morals and politics. Finally, we proceed to a systematic criticism of the idea of the State as it was proposed by the Marxist approach.

Keywords: Estado, Soberanía nacional, Materialismo filosófico, libertad, igualdad, fraternidad, sujeto político, espacio axiológico, etica, moral, política, marxismo.

\section{1. ¿Proletarios o ciudadanos?}

Cuál es y cómo podría definirse el sujeto político en el siglo XXI en una España que no puede tolerar ningún intento de apropiación partidaria de su soberanía nacional, la que reside en la nación española. El marxismo concebía el advenimiento del comunismo como el proceso revolucionario en virtud del cual una clase, el proletariado, se hace con la soberanía nacional. El proletariado es una clase social dentro del Estado, pero es, además, según el marxismo, la clase universal: "Proletarios de todos los países, uníos". Se suponía que esa unión proletaria acabaría arrasando con el Estado como estructura de dominación burguesa. La realidad histórica puso ante los marxistas la evidencia de que los proletarios salían en defensa del Estado y no de su clase. Este contratiempo se fue sorteando con el argumento de que en virtud de su alienación los proletarios asumían los intereses de la burguesía dominante. 
La idea de la existencia de una clase social universal proletaria procede de un enfoque genérico de tipo sociológico que, abstrayendo todas las determinaciones históricas particulares de cada pueblo, es capaz de establecer una clasificación abstracta de pretendido carácter universal. Pero esa universalidad sociológica ya digo que sólo se alcanza a costa de disolver las diferencias particulares que en la vida de los pueblos son absolutamente determinantes. Científicamente cabe distribuir las sociedades en términos de clases, haciendo abstracción de las naciones, pero el origen de las clases sociales está en la conformación histórica de las sociedades políticas. Se trata de una dialéctica muy interesante entre Historia y lo que podríamos llamar Geografía política. De modo que el marxismo procede del siguiente modo: parte de una categoría sociológica genérica, la clase social, abstraída de sus determinaciones históricas y políticas concretas y la convierte en actor político histórico, pretendiendo que asuma un papel histórico preciso, cuando en los propios estudios históricos marxistas se hace evidente que hay que escudriñar en los entresijos de todo acontecimiento histórico para desentrañar el entramado de clases que está enfrentándose en cada caso.

En definitiva, la lucha de clases no es una estructura de tipo sociológico, un sistema de clasificación científica de la sociedad, sino la expresión simplificada de los modos de apropiación de la soberanía nacional dentro de cada nación política, una vez que se superaron las soberanías monárquicas del Antiguo Régimen, por supuesto. La lucha de clases, así entendida, sólo puede darse en el seno de cada Estado, aunque puedan eventualmente intervenir $-y$ de hecho intervienen- en esa misma lucha otros Estados. De modo que la clase universal proletaria sólo puede serlo a través del Estado correspondiente, y esa es su dialéctica. Además, de hecho, fuera de esas determinaciones, esas clases sociales se desvanecen absolutamente en la forma de las masas de refugiados a las que contribuimos los países europeos con la OTAN de modo decisivo. La única salvación de un refugiado es alcanzar una nueva nacionalidad, que es lo justo, aquello que le permite volver a vivir con dignidad.

La única universalidad a la que podemos aspirar es aquella que se perfila en términos de ciudadanía, esto es, la que corresponde a la soberanía nacional, aquella que se prefigura en los límites de una sociedad política. Esa universalidad es un precipitado por decantación de la lucha de clases por la soberanía en el seno de cada Estado. Pero la clase "universal" que decanta en el proceso de consolidación de los Estados nación está a una escala diferente a aquella en la que se ejercita la lucha de clases, aunque sólo a través de ella se manifiesta, y es la idea de ciudadanía. 
No queda más remedio que asumir que la idea de ciudadano es la noción más universal desde un punto de vista político. Es, a su vez, práctica y precisa, aunque abstracta. En ella se expresa tanto la figura del proletariado como la de la burguesía, en ella se expresan las diferencias entre hombres y mujeres, en ella se reinterpretan y ecualizan las culturas y las razas y, por supuesto, también se ecualizan las regiones, las ciudades y los pueblos, las provincias y las comarcas y hasta las familias. No hay alternativa.

Ahora bien, sólo desde esa figura de ciudadano como "universal distributivo" dado en cada Estado es concebible la noción universal de hombre como persona moral, tal y como lo recoge la Declaración Universal de los Derechos Humanos. Las sociedades políticas han procedido disolviendo las diferencias culturales y transformándolas en diferencias sociológicas, ecualizándose por tanto todas ellas. Y es a través de esa ecualización como se ha ido perfilando la figura de la idea de persona moral universal. Esta es la dialéctica que está presente en el debate entre Sócrates y Protágoras en relación con la educación cuando se discute la diferencia entre Ciudadano y Hombre. Pero el dialelo moral estaría aquí delimitado por el hecho de que esa idea de persona moral universal sólo puede darse, en sentido material, práctico, efectivo, a través de los ciudadanos reales circunscritos por sociedades políticas en cuyo seno mantienen y articulan sus conflictos.

Y esta es su dialéctica. Los Derechos humanos no son suficientes para garantizar una vida digna a aquellos refugiados que pierden su condición ciudadana. Sólo los Estados, en virtud de su fortaleza relativa, garantizan esa dignidad, incluso para aquellos refugiados que llegan a su territorio. Pero esa fortaleza sólo se alcanza fortaleciendo la soberanía nacional. No todos los Estados son iguales, ni todos pueden garantizar el mismo grado de justicia, igualdad y libertad a sus ciudadanos y ello depende de su soberanía en el ámbito de una dialéctica entre Estados efectiva que nos afecta de modo decisivo.

Lo siguiente es ahora analizar los factores basales, corticales y conjuntivos que contribuyen a consolidar la soberanía nacional, la igualdad de oportunidades y la justicia social en la dialéctica de Estados desde una perspectiva materialista. 


\section{Comunismo de ayer y de hoy}

En este pequeño artículo quiero hacer un comentario relativo al renovado uso de la palabra "comunismo" como arma arrojadiza entre enemigos políticos. Se propone también una idea de qué puede significar hoy por hoy ser comunista.

$\dot{2}$ Tiene sentido que se acuse de comunistas a partidos como Podemos, o partidos secesionistas llamados de izquierda? El único sentido que puede tener esta acusación tiene que ver con su posible disposición hacia el secesionismo. La razón por la que esto es así es la misma por la que el comunismo decimonónico no tiene absolutamente nada que hacer, y nada que ver, con el actual concepto de comunismo en el contexto de una sociedad como la española entendida como un sistema democrático sostenido por el principio de la soberanía nacional.

El comunismo original es un movimiento político revolucionario que, apoyándose en la doctrina marxista de la lucha de clases, pretende la imposición de la dictadura del proletariado como medio para la emancipación de los hombres y la eliminación definitiva y en última instancia de todo Estado posible. Ahora bien, esa dictadura la regenta el Partido Comunista, que es el "único" partido posible dentro de ese sistema. Y, como la emancipación definitiva de la Humanidad resulta ser una aspiración metafísica impracticable, la dictadura del proletariado deja de ser un medio y se manifiesta como el verdadero fin de la revolución comunista.

Si el Partido Comunista necesita llevar adelante un proceso revolucionario no es sólo para hacerse coyunturalmente con el poder, sino para abrogarse la propia soberanía de la nación. Como, en esas circunstancias la soberanía residiría en el Partido Comunista, la lucha de clases como tal "desaparece", y se transforma en un programa práctico de reeducación y emancipación para todo el conjunto de individuos que están fuera del partido (las luchas pueden darse, sin duda, en el seno del partido, pero se les llama "purgas"). No es sólo un error histórico todo el entramado de campos de trabajo que desarrolló la Unión Soviética. Es como el modelo del Antiguo Régimen en su forma ilustrada, si se quiere, en la que la soberanía residía en el Rey, o en la aristocracia por él liderada, mientras el pueblo recibía con abnegado sometimiento las leyes más luminosas. Igualmente, el Partido Comunista, liderado por hombres que han sabido superar la conciencia alienada de clase, detenta la soberanía que tutela el largo proceso de la emancipación de toda la sociedad. Por eso preguntaba Lenin: "¿Libertad, para qué?" El fin es el medio por el que la revolución consolida sus medios como fines.

Sólo con la superación del llamado Antiguo Régimen pudo desplegarse el proceso de lucha de clases entre la burguesía y el proletariado. Ese conflicto generado por el hecho de que la realeza pierde la soberanía, es decir, la propiedad absoluta de tierras, bienes y personas, fue 
resolviéndose de diversos modos según las circunstancias particulares de cada nación histórica. Rusia no pudo aprovechar la coyuntura provocada por su victoria contra Napoleón porque el Zar lideraba la resistencia al invasor. Sin embargo, en España, donde el Rey se había pasado al enemigo, quedó en manos de los españoles la defensa de su tierra, dando lugar a uno de los procesos más genuinos de conformación de la soberanía nacional. Una vez reconocida en la Constitución de 1812, la soberanía pudo volver a perderse, pero siempre ya como una usurpación indebida y reparable. En Rusia, el fin del antiguo régimen trajo consigo una débil revolución burguesa (la de Kerenski) e inmediatamente la revolución de octubre, en la que se consuma la apropiación de la soberanía por parte del Partido, lo cual explica muchas de las tensiones que hubieron de sofocarse a golpe de látigo en aquellos momentos con grupos que han pasado a la historia como muy radicales, pero que no estaban dispuestos a que la soberanía recayera ahora en los bolcheviques. Y tampoco pudo la URSS desarrollar su bien merecida soberanía nacional soviética con la victoria en la que ellos llaman con acierto "la Gran Guerra Patria", precisamente porque el modelo político creado por la usurpación de la soberanía por parte del Partido Comunista lo hacía imposible; y ese es el principal lamento de disidentes, como Alexander Zinoviev, que no pretendían destruir la URSS sino convertirla en una nación soberana precisamente limitando el poder del partido comunista.

La lucha de clases es, en definitiva, una lucha por la soberanía y, por lo tanto, sólo puede darse en el seno de una nación históricamente consolidada. En la medida en que se canaliza a través de los partidos políticos, sólo cristaliza por decantación, como soberanía nacional, cuando ningún partido es capaz de imponer su particular dictadura, es decir, cuando la tensión de fuerzas puede al menos llegar a bloquear entre sí esas aspiraciones. Este es el fundamento de cualquier sociedad democrática como la nuestra. Los partidos pueden negociar la gestión de la soberanía pero no apropiársela, que es lo que hoy consideramos incurrir en corrupción.

Los proletarios soldados de los ejércitos en las guerras mundiales fueron, como los españoles de la guerra de independencia, ante todo, defensores de su tierra. En la Guerra Civil española, aunque se pulverizó la soberanía nacional, ninguno de los bandos renunció a España, salvo los secesionistas traidores al gobierno republicano. Hasta el punto de que el presidente de la República, Don Juan Negrín, llegó a decir: "Y si esas gentes van a descuartizar a España, prefiero a Franco. Con Franco ya nos las entenderíamos nosotros, o nuestros hijos, o quien fuere. Pero esos hombres son inaguantables." Muchos anarquistas consideraban la guerra civil como otra guerra de independencia, por ejemplo.

Los únicos partidos que atentan hoy en España contra la soberanía nacional siguen siendo los partidos secesionistas $y$, aunque se llamen "republicanos", nada hay en ellos de aquellas viejas aspiraciones, sino las 
mismas por las cuales estos partidos secesionistas traicionaron a la República cuando pudieron. Su objetivo político es apropiarse de un territorio en el que viven millones de españoles. La lucha de clases se manifiesta como conflicto entre una clase burguesa en la vanguardia del secesionismo y un proletariado claramente español, con todos los adjetivos que Pujol y Torra, entre otros, les han dedicado. Pero la lucha de clases inevitable sólo es gestionable desde la soberanía nacional común.

Cuando los partidos de izquierda apoyan el secesionismo no están defendiendo la apropiación por parte de un partido de la soberanía de Cataluña o el País Vasco, sino de toda la nación española, porque sólo así pueden hacerse con la propiedad de la parte del territorio que ellos aspiran a dominar bajo un régimen que, como en la URSS, sólo podrá estar gestionado por partidos de la misma ideología secesionista. No caben partidos no secesionistas. Y los millones de españoles que no son independentistas, alienados por la ideología franquista españolista retrógrada, y marcados por arrastrar su vida sin "lazos" amarillos, deberán poco a poco ser reprogramados -emancipados-, y convertidos a la causa, o purgados; para lo cual siempre es interesante que se utilice un idioma particular y un aparato de propaganda que, aunque sea una basura, repita hasta la saciedad aquella asquerosa sentencia goebbelsiana: si la mentira se repite suficientes veces, acaba siendo verdad.

Paradójicamente, los partidos que actualmente defienden y apoyan la apropiación de la soberanía nacional por parte de una minoría actúan como los partidos comunistas revolucionarios que en el siglo $X X$ pretendieron cancelar la lucha de clases mediante una dictadura del proletariado en la que la soberanía residiría en el Partido, aunque coreaban la Internacional.

Ahora bien, ¿̇qué comunismo cabe en el siglo XXI en una España en la que la soberanía nacional ya no es negociable y, por tanto, la dictadura del proletariado o del nacionalismo secesionista es imposible? A mi modo de ver, el comunismo del siglo XXI debe concentrarse en el estudio y la defensa de aquellos factores (basales, corticales, conjuntivos) que contribuyen a consolidar la soberanía nacional, la igualdad de oportunidades y la justicia social en la dialéctica de Estados.

Gijón, a 29 de diciembre de 2018 


\section{Soberanía y Materialismo electoral}

1. Según el libro de Gustavo Bueno, Ensayo sobre las categorías de las ciencias políticas, publicado en La Rioja en el año 1991, la estructura de toda sociedad política se compone de tres capas: la capa conjuntiva, la capa basal y la capa cortical. La capa conjuntiva regula las relaciones entre los individuos de dicha sociedad política (lo que en el marxismo se llamaría las relaciones de producción, la estructura). La capa basal se refiere a la articulación de las relaciones que median entre los individuos de una sociedad política y su territorio. En este sentido dice Bueno: "La capa basal no podrá entenderse como el conjunto de los recursos naturales de la sociedad política: estos recursos han de estar "conceptualizados" es decir, descubiertos o inventados; de otra suerte es como si ellos no existieran".

La capa basal es pues el entramado objetivo articulado que estructura nuestra existencia política: todas las instalaciones y morfologías que regulan, delimitan y articulan las operaciones y relaciones entre los sujetos, desde los sistemas de abastecimiento, redes de comunicaciones, entramados productivos, territorio, geografía, flora, fauna, etc., del Estado. Por supuesto, es mucho más que solamente la infraestructura de la sociedad política, porque no se refiere sólo al modo de producción, que sí puede ser genéricamente equiparable entre estados por su momento histórico en una perspectiva genérica, sociológica o geográfica, sino a todo aquello que convierte a una sociedad política en una singularidad irreductible a otras; y sin esta suposición sería impensable por ejemplo la propia historia; de hecho la historia de dicha sociedad política se despliega a través del territorio entendido como patria, lugar donde yacen nuestros antepasados. En este sentido, el espacio en política es sustancialmente tiempo, historia.

Finalmente, la capa cortical se refiere a la defensa de las fronteras, a la gestión de las relaciones con otros países, las posibles alianzas y federaciones así como el ejército, la diplomacia y la propia guerra. En el marxismo existe también la "superestructura" de la sociedad, conformada por ideologías, el Estado, la Historia, la Religión, etc., pero todo ello quedaría redistribuido según estas capas. Bueno dedica análisis muy jugosos a este asunto, en todo caso, en este libro magnífico y de lectura obligatoria para cualquier político español que se precie.

Ahora bien, el núcleo de la vida política, según Bueno, es una actividad, una praxis, que busca la supervivencia del sistema social mediante operaciones con términos que aseguran la recurrencia de la sociedad de referencia. De manera que la verdad de la política se llamará Eutaxía, que viene a significar el orden recurrente, la permanencia de la sociedad, el buen orden. Ahora bien, como quiera que en cualquier sociedad política todas las actividades humanas de "primer orden", que pueden darse tanto en el eje circular, como en el eje angular, como en 
el radial (nos referimos aquí a la inapelable teoría del Espacio Antropológico de Gustavo Bueno), deben ser coordinadas, bloqueadas, impulsadas y en definitiva subsumidas en función de la eutaxía de esa misma sociedad política, decimos que las acciones dadas en el eje circular conforman la capa conjuntiva de la sociedad política; así, las acciones dadas en el eje radial conforman la capa basal de la sociedad política y las acciones dadas en el eje angular conforman la capa cortical de la sociedad política.

2. Según estas tres capas y las dialécticas que corresponden a las relaciones que cabe establecer entre ellas, podemos delimitar una reinterpretación materialista de la soberanía nacional: la soberanía de una sociedad política se definirá en términos de su soberanía conjuntiva, de su soberanía basal y de su soberanía cortical. La soberanía sintetiza pues la propia fortaleza del Estado, que no puede quedar cifrada de ningún modo más allá de su capacidad para perdurar en el tiempo eutaxía-. Rousseau comenzaba su Contrato social advirtiendo que todos los Estados tienden a degenerar. Así el arte del buen gobierno tiene que ver con el sostenimiento del Estado en el tiempo, que Bueno define con la palabra "eutaxía", o buen orden político. Pero esa recurrencia, esa eutaxía, debe darse a través de las tres capas de la sociedad política. Por ello, podríamos decir que la eutaxía de la capa conjuntiva se expresa en términos de la idea de Libertad, mientras que la eutaxía de la capa basal se expresa en términos de la idea de lgualdad, y la eutaxía de la capa cortical se expresa en términos de la idea de Fraternidad.

Identificada la eutaxía de cada capa por las ideas de Libertad, Igualdad y Fraternidad, se hace evidente que la soberanía de las diferentes capas mantiene una congruencia dialéctica; es decir, no se trata de los tres ejes de un espacio tridimensional en el que los valores de cada uno de los ejes se puede entender como independiente de los valores de los otros ejes, como ocurre en la perspectiva genérica en la teoría del Espacio Antropológico. En efecto, en un espacio tridimensional los valores de cada eje no son separables entre sí, pero sí son disociables, porque los valores pueden ser independientes entre sí; sin embargo en la estructura del Estado los valores dados en una de las capas determinan los valores correspondientes de las otras. Esto significa que en política no toda combinación de términos según las tres capas es posible y, en función de los valores que se establezcan en uno de los ejes, varía también el valor del resto, por eso no hablamos de ejes, sino de capas. Y esto supone, a su vez, que en el juego de la política cuando se apela a determinados parámetros de una cierta capa explícitamente, se están dando a su vez otros parámetros ocultos en otras capas, que se articulan como consecuencia de aquellos. Y así es como en la batalla mediática de las campañas electorales los candidatos y los partidos actúan como los magos, ofreciendo al cliente, votante, o vendedor de voto, sólo una parte del todo, aquella que puede resultar más atractiva al público 
elegido, ocultando las posibles consecuencias o las estrategias y medios preparados para poder llevar a cabo, en su caso, semejantes propuestas explícitas. Normalmente el votante considera que esos valores se dan de modo independiente a otros no explícitos, precisamente ese es el efecto buscado, en una suerte de "efecto Kulechov" ideológico.

De hecho, cuando reducimos el problema de la soberanía a la capa conjuntiva parece que con la cuestión de la división de poderes y el Estado de derecho el asunto parecería estar resuelto. Pero es evidente que una concepción materialista del Estado no puede mantenerse en este nivel de abstracción ("formalismo político" lo llama Gustavo Bueno). Entre otras cosas porque la Igualdad política depende de la gestión de la capa basal, y la Fraternidad depende de la propia fortaleza del Estado. Ahora bien, la fortaleza del Estado requiere también la regulación de la soberanía correspondiente a la capa basal. La capa basal, de hecho, está estructurada, según Gustavo Bueno, en paralelo con los tres poderes de la capa conjuntiva (poder ejecutivo, poder legislativo y poder judicial), por un poder planificador, un poder gestor y un poder redistribuidor.

3. Ahora, la cuestión es cómo se expresaría esa soberanía nacional desde cada capa, teniendo en cuenta que la soberanía nacional es un proceso de decantación que se conforma en el conflicto político cuando este conflicto comienza a regularse de manera tal que ningún partido, por así decir, puede apropiarse de ella. Desde la capa conjuntiva la soberanía nacional se expresaría en la determinación del conjunto de disposiciones orientadas a la limitación objetiva de acceso al poder de cualquier partido, o grupo político. La idea del Estado de derecho y la división de poderes es el principio de garantía de la soberanía cuando la entendemos como la configuración de una estructura tal que hace imposible a cualquier partido político desbordar los límites legales en el ejercicio del poder. Pero ¿̇cómo el Estado puede hacer efectiva esta limitación estructural? Pues me parece que sólo la fortaleza del Estado medida en términos de su capa basal y de su capa cortical puede efectivamente mantener esos límites, porque a nadie se le escapa que la tendencia de los grupos políticos enfrentados es en principio omnímoda y su moderación sólo fruto de su debilidad.

Desde la capa basal la soberanía nacional se debería medir, podríamos decirlo así, por la determinación del conjunto de disposiciones orientadas a la preservación de la Patria, si es que entendemos por Patria la manifestación secular del territorio como escenario complejo en el que se ha ido tejiendo la vida, en nuestro caso, de los españoles. Urdimbre tejida de tramas pasadas que entrelazan y perfilan los nuevos dramas de nuestras vidas cotidianas, a cuyo través dialogamos con los antepasados. En este sentido, se pregunta Gustavo Bueno en el libro que antes hemos citado, página 311: "¿̇n nombre de qué principios el Estado debe ser 
sólo subsidiario, debe ser sólo guardián de noche? Bajo el pabellón del deber ser se esconden los intereses de empresas nacionales 0 multinacionales, o de organizaciones religiosas, también multinacionales; pero estos intereses no miden su fuerza real por el supuesto imperativo del deber ser, sino por la capacidad real de su poder efectivo cuando él se enfrenta con el poder del Estado." La soberanía de la capa basal debe sobreponerse ahora a los intereses de los grupos enfrentados, a los intereses partidarios que pueden hacerse con el poder y acometer desde la capa conjuntiva un espolio insoportable a la patria común, como dice Bueno, apelando quizás a un deber ser intolerable. Aquí es donde se cifra la gran batalla por la soberanía y el principal de los problemas de la política.

El deber ser del neoliberalismo que impera en Europa al servicio de intereses de otros países condiciona y fuerza muchas políticas en España contra su capa basal. Desgraciadamente, no son pocos los partidos que apelan de nuevo en España a este deber ser, a principios que apelan a un egoísmo natural, etc. De manera que el único arreglo es ir poco a poco desmontando el Estado; desmontándolo desde el ejercicio de los poderes de la capa conjuntiva, cumpliendo finalmente con los intereses o bien de otros países o bien de multinacionales, empresas, partidos, etc.

No obstante, ideologías identitarias, nacionalistas y xenófobas pueden jugar un papel decisivo contra la soberanía de la capa basal. Los partidos nacionalistas secesionistas en España ejercen de hecho el poder de la capa conjuntiva del Estado, pero lo utilizan con el fin de desmantelar y descomponer la capa basal de manera explícita. De tal modo es así que no han tenido el menor reparo en buscar el apoyo de terceros países, en diferentes ocasiones como se ha conocido. Y i cómo se puede defender la soberanía de la capa basal de la intervención corrupta del poder de la capa conjuntiva? Por una parte, por la presencia de partidos políticos decididos a defender la capa basal aprovechando las propias estructuras del poder de la capa conjuntiva, limitando por ejemplo la capacidad de intervención que un gobierno puede tener en la privatización de los bienes públicos, igual que la tienen limitada para separar una parte del territorio. Yo nunca he entendido muy bien qué legitimidad puede tener un partido político, el que sea, que gobierna y gestiona la nación durante un período de tiempo tan corfo, para decidir de modo irreversible acerca de estructuras basales absolutamente públicas y necesarias. La privatización o no privatización de los bienes del Estado no parece que pueda estar en manos de un gobierno, salvo que ese gobierno ostente la soberanía del Estado, cosa que no hace, lo mismo que no lo está la partición del territorio.

La soberanía de la capa cortical, en la medida en que tiene que ver, por ejemplo, con la defensa de nuestras fronteras, con la gestión y regulación de las relaciones entre países está totalmente determinada por lo que Bueno ha llamado la dialéctica de Estados. Un Estado acomete sus relaciones exteriores en función de su fortaleza, de la soberanía 
conjuntiva, sin duda, y de la soberanía basal. Esas relaciones están siempre mediadas por el equilibrio de fuerzas y por tanto aquí el juego de la diplomacia es decisivo. Pero para que esas dialécticas resulten eficaces es necesario, desde luego, controlar las tendencias divergentes de los grupos enfrentados en la política nacional, evitando que estas tensiones puedan servir a los intereses de otras naciones. Por lo demás, España deberá jugar sus cartas en el tablero internacional teniendo en cuenta su fuerza relativa y el hecho de que otros países y coaliciones de países, multinacionales, etc., ejercer un poder que debe ser lidiado de la manera que menos afecte a nuestra soberanía basal, y conjuntiva.

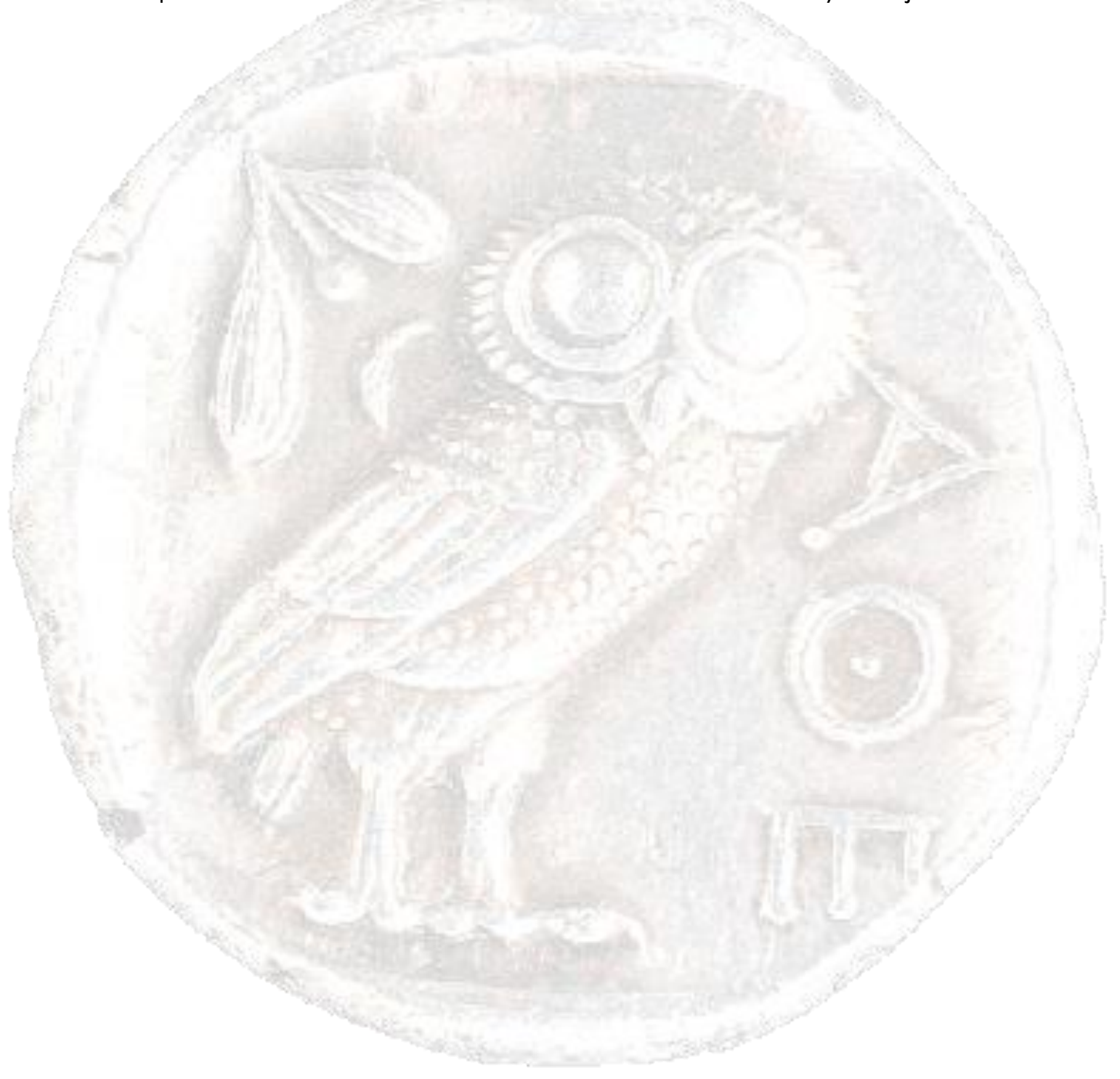




\section{Dialéctica de la soberanía en las tres capas del Estado}

Vista ahora la sociedad política desde la perspectiva materialista de las tres capas, es decir, vista la Libertad como medida de la soberanía de la capa conjuntiva, la lgualdad como medida de la soberanía de la capa basal, y la Fraternidad como medida de la soberanía de la capa cortical, resulta evidente que el aumento de la Igualdad social requiere una reducción de la libertad, y viceversa; la libertad puede contribuir a la desigualdad. Podríamos decir que la Igualdad y la Libertad, vistas desde la perspectiva de sus respectivas capas, son inversamente proporcionales. Una mayor libertad política puede contribuir a una mayor desigualdad basal, al tiempo que la igualdad exige la imposición de ciertas limitaciones a la libertad económica, y política. Del mismo modo, la Fraternidad al depender de la fortaleza del Estado consideramos que ella está en función de la resultante de la relación inversa entre lgualdad y Libertad.

Muchas veces ocurre cuando escuchamos a partidos políticos como Ciudadanos o Partido Popular, y últimamente a Vox, expresar su defensa de la libertad, que la proponen como un bien por así decir abstracto y universal, sin parámetros. Lo mismo ocurre por ejemplo cuando escuchamos aquella maravillosa canción de Labordeta, en la que decía: "Habrá un día en que todos al levantar la vista veremos una tierra que ponga Libertad." Bien, pues esta canción, por ejemplo, remite a una idea de libertad que seguramente no quisiera compartir con la libertad que defienden estos partidos a los que nos hemos referido. Al menos no creo que estos partidos quieran tomar como himno de su causa este tema de Labordeta. No obstante, algo tienen en común, desde luego. Y se refiere precisamente a esa idea de Libertad, vista desde la capa conjuntiva. Libertad de partidos políticos, Democracia, en definitiva, donde cada uno pueda defender sus ideas. Libertad como espacio común de discusión. Algunos pueden considerar incluso que nuestra democracia ha degenerado por el hecho de que la Demagogia hace estragos, como ya señalaba Platón y Aristóteles. Sin embargo, muchos hay hoy que simpatizando con la canción de Labordeta, agreden y dificultan la tarea política a sus contrincantes. Esa presión contra los partidos contrincantes es un acto contra la libertad entendida desde la perspectiva conjuntiva, sin duda.

Pero, desde luego, en la medida en que una sociedad política es una sociedad cuya esencia consiste precisamente en el ejercicio de un poder capaz de articular las tendencias divergentes irreductibles de grupos en conflicto, es evidente que una democracia como la española más que degenerada por la demagogia y los populismos, está viviendo un tiempo en el que se desatan los conflictos, la presencia activa de los grupos y las tensiones. Porque degenerar supone que efectivamente entendemos el cuerpo político como una unidad metafísica, y no lo es. Ahora, más allá 
de esa libertad como condición de la democracia y del estado de derecho, de la separación de poderes, no puede haber mucho en común entre los partidos referidos, que se consideran de Derechas, y las ideologías llamadas de Izquierdas. Por qué. Porque el liberalismo al que apelan los partidos de derecha no se refiere a la capa conjuntiva, sino a la capa basal. Pero si referimos la libertad a la capa basal, entonces estamos ante una clara apuesta por la desigualdad, y por una limitación de los poderes regulativos planificadores, gestores y redistribuidores del Estado. Entonces, podemos decir que la Libertad esgrimida por los partidos de derechas es una apuesta por la desregulación de la capa basal del estado que garantiza la lgualdad; y eso es precisamente un factor clave para la degeneración de un Estado.

Tomemos la tercera capa que propone Gustavo Bueno, la capa cortical. En esta capa se regula la relación del Estado con otros Estados, las fronteras, el territorio, la diplomacia y el ámbito de lo que llamamos la dialéctica de Estados. Si la idea fuerza de la capa conjuntiva es la Libertad, y la de la capa basal es la lgualdad, consideramos que la idea fuerza de la capa cortical será la Fraternidad. Ahora bien, como la fraternidad del Estado está en función directamente proporcional a la fortaleza del Estado es, diremos, directamente proporcional con la Igualdad dentro de la capa basal del Estado, mientras que será también inversamente proporcional con la Libertad de la capa conjuntiva, puesto que ella debilita la capa basal.

Un partido puede defender la Libertad, pero si lo hace con todas las consecuencias, progresivamente tenderá a reducir la igualad entre los ciudadanos, puesto que la igualdad exige la intervención del estado para redistribuir la riqueza e imponer los mismos criterios más allá de la capacidad económica de cada uno. La igualdad siempre supone el ejercicio de la fuerza del estado, y esa fuerza se ejerce contra la libertad. La igualdad es el principio que rige los Estados precisamente porque todo Estado está conformado por fuerzas divergentes que tienden a ejercer sus "derechos" frente al resto. Esa tensión interna entre las partes del Estado sólo puede regularse por el ejercicio de la fuerza basada en la igualdad basal.

Normalmente no deberían existir partidos que defiendan la desigualdad dentro del Estado. Pero es precisamente sobre este principio sobre el que se articuló gran parte del discurso marxista y anarquista contra el Estado. Se decía entonces que el Estado es un instrumento de la clase burguesa para perpetuar su domino y su situación de privilegio. Por eso Manuel Sacristán llegó incluso a clamar contra la Filosofía, suponiendo que ella era la que alimentaba ideológicamente al Estado represor. Sin embargo el Estado, desde nuestra perspectiva materialista, no puede quedar reducido a sus condiciones particulares de existencia. El reduccionismo sólo conduce al relativismo. Sin embargo, en España han surgido ya partidos que no sólo defienden a un grupo social frente a otros, sino que explícitamente hacen ostentación de sus principios supremacistas. Son los 
partidos nacionalistas. En ellos se juntan los vicios de la negación de la libertad, puesto que se pretende forzar la soberanía nacional con el fin de defender las desigualdades; el vicio de la desigualdad, puesto que defienden una diferencia cuya solución sólo puede darse por la apropiación de una parte de la patria común; y el vicio de la negación de la fraternidad, al renunciar a la hermandad histórica e intergeneracional de todos los españoles. De hecho, sólo en las regiones más enriquecidas por el esfuerzo común de toda la nación española tienen fuerza los partidos secesionistas. En ellos se cifra precisamente el máximo valor de la degeneración política det Estado.

Por eso podemos decir que España se enfrenta en estos momentos a su máxima degeneración, sólo superada por el estallido de una guerra civil; cuando ya la soberanía nacional ha desaparecido. Hay un riesgo evidente, percibido por toda la sociedad, porque ya se ha probado, un riesgo de que los partidos políticos no acaten los resultados de las urnas. En España estamos llegando, peligrosamente, a esta posible circunstancia, como ya se puso de manifiesto en las elecciones andaluzas.

Del mismo modo, el problema de la fraternidad tiene que ver con la concepción del Estado y de sus relaciones con el resto. La fraternidad capitalista se ejerce hacia adentro. Los estados, aprovechando el clamor ético, absorben inmigrantes para poder explotarlos en trabajos precarios que se demandan porque el capitalismo los requiere así. Sin embargo, la fraternidad socialista no tratará tanto de absorber inmigrantes, mano de obra barata, sino de proyectarse en la reorganización y fortalecimiento de otros Estados precisamente reorganizando su capa basal y su igualdad. Es evidente que sólo este enfoque puede solucionar el problema de la inmigración al que se enfrentan todos los países europeos. Si no se afronta así el problema es porque desde la perspectiva capitalista esta fuente de mano de obra resulta muy rentable. 


\section{Un problema de máximos y mínimos}

Tomamos ahora los tres parámetros, Libertad, Igualdad y Fraternidad, correspondientes a las tres capas de la sociedad política. Es evidente que estos parámetros pueden adquirir distintos valores, en una gradación sin duda borrosa pero perceptible. Precisamente por su carácter borroso ensayaremos solamente sus valores máximos y mínimos, teniendo en cuenta que estos valores no son independientes entres sí, como hemos dicho. Podríamos organizar de un modo muy grosero pero crítico las posibilidades efectivas y las ideales que se derivan para el votante en una sociedad política como la española, en la que precisamente porque la soberanía reside en toda la nación, se ofrecen distintas opciones políticas.

El socialismo podría definirse ahora por aquellos modelos políticos que se orientan hacia la igualdad. La redistribución de la riqueza, la intervención estatal y la puesta a punto de las condiciones que garanticen a todos los ciudadanos las mismas oportunidades suponen una política centrada en la capa basal, determinada en la búsqueda de la igualación de los individuos. Esto supone subordinar la capa conjuntiva y la libertad a la capa basal. Se dirá que no hay verdadera libertad si no hay igualdad. Esta es la dialéctica. La capa basal dirige y regula la gestión política de la capa conjuntiva. Los países comunistas, y particularmente la URSS, trataron no solamente de reducir la diferencia salarial entre los más pagados y los menos pagados, sino de hacer políticas profundamente centradas en la capa basal, con sus planes quinquenales, por ejemplo, lo que ha dado como resultado países extremadamente poderosos en sus posibilidades, pero finalmente colapsados por la recurrente renuncia a la libertad: "Libertad, ¿̇para qué?" -decía Lenin. Es, en el fondo, un modelo ilustrado.

No obstante, hay que decir que ningún país, y tampoco España, puede organizarse actualmente sin una planificación sistemática de la economía. De hecho tenemos elecciones anticipadas precisamente porque no se han podido aprobar los Presupuestos Generales del Estado. En España la planificación se hace anualmente a través de los presupuestos. El sentido esencial de cualquier Estado es la gestión, planificación y redistribución de los recursos. Por esa razón, cuando los partidos políticos buscan el poder y lo obtienen, este poder se sustenta precisamente en la capacidad que el gobierno de turno tiene para la gestión de los recursos. Ahora la cuestión está en cómo debe realizarse dicha gestión. ¿̇iene legitimidad un gobierno cualquiera para privatizar bienes públicos? Aunque lo apoye una gran mayoría de la cámara, ¿puede permitirse a un partido político la disposición de la propiedad colectiva y su venta y privatización? Precisamente esta cuestión nadie se atreve a discutirla a fondo en España actualmente. Todos los partidos han privatizado a discreción. El escándalo de Endesa que acaba de saltar es 
una pequeña muestra. La corrupción política del PP en Madrid tuvo como contexto la privatización del sistema público de salud, una verdadera atrocidad. Vergonzoso y repugnante es el fenómeno de las puertas giratorias, que acogen amablemente a los políticos que previamente han contribuido a la privatización de empresas públicas. La privatización de las Cajas de Ahorro ha sido también un verdadero escándalo, que acabará hundiendo sin remedio a las zonas rurales, y nadie discute hoy por hoy la necesaria privatización de Bankia, un banco rescatado y, por tanto, público, que debería jugar un papel notorio en la planificación económica y seguir siendo aprovechado por el Estado, no privatizado. Sin embargo, ha calado hasta el tuétano en la sociedad española que debe ser privatizado Bankia. Es ridículo, desde luego, sobre todo por lo que nos ha costado recuperarlo, una verdadera barbaridad de dinero. De hecho, aunque estamos en un sistema capitalista, hay que decir que es un sistema capitalista totalmente subvencionado. Las empresas medianas y grandes reciben ayudas públicas por contratar, por el tipo de contrato, por el tipo de trabajador, reciben subvenciones por las inversiones, reciben subvención pública si no pueden gestionar su propia quiebra; el Estado se encarga de afrontar gastos en todos los casos; sin embargo con los pequeños autónomos la situación es desastrosa. De modo que verdaderamente estamos ante un fenómeno complejo que, sin embargo, podría resumirse diciendo que la economía regulada y controlada por el Estado en este momento actúa del siguiente modo: se colectivizan los gastos, y se privatizan los beneficios. El resultado es una sociedad totalmente subsidiaria y dependiente desde el punto de vista económico. Lo hemos visto en casos de escándalo, como el de Vestas en León, o el de Alcoa. El Estado adelgaza en su propia estructura pública mediante la privatización pero a cambio se convierte en una especie de sistema circulatorio disperso a través del cual insufla dinero para financiar todo tipo de iniciativa privada y afronta el gasto de las inversiones, mientras que los beneficios posibles se privatizan. Estas circunstancias sin duda alimentan muchos de los discursos abolicionistas contra el Estado, como cuando los Ludditas consideraban a las máquinas las causantes de sus problemas de desempleo. No eran las máquinas, sino las relaciones de producción en las que se inserta su uso, nos recordaba Boris Hessen, al igual que no es el Estado sino las relaciones de producción las que lo convierten en un instrumento contra la igualdad y la libertad.

En el otro extremo estaría el capitalismo que, apelando a la idea de Libertad, reduce al mínimo la igualdad, renunciando a la gestión, redistribución y regulación de los bienes públicos, un Estado mínimo, Estado centinela que a lo sumo afronta labores de defensa y cuya función consistiría en facilitar los negocios. La mayor perversión se producirá cuando un partido instrumentaliza la capa basal del Estado para desmantelarla en beneficio propio, como ha ido ocurriendo en España desde que comenzó la Transición. Desmantelamiento de las estructuras basales del Estado (privatizaciones masivas) apelando a argumentos conjuntivos (competencia, racionalidad, ahorro, eficacia), 
que desfondan la soberanía basal y por tanto dirigen el Estado hacia un proceso degenerativo. En el límite esta idea tiende a la disolución de los Estados en lo que puede llamarse el anarco-capitalismo de la libertad individual. La fraternidad alcanzaría un máximo hacia el interior de los Estados disolviendo las fronteras, a costa de abandonar completamente las labores de protección social, y no tendría ningún sentido la fraternidad exterior, salvo que se dirigiera a facilitar la disolución de las fronteras y la destrucción de otros Estados, pero esa labor no podría corresponder a un Estado mínimo, sino a un Imperio, como por ejemplo el Imperio estadounidense. Es el liberalismo del Laissez faire y laissez passer. Así procede la ideología de Jeremy Rifkin en su famoso e influyente libro El fin del Trabajo. Rifkin propone como una verdad incontestable el fin de los Estados, la sustitución de los empleados públicos por voluntariado cualificado y una economía abierta y transfronteriza; al tiempo que el Estado y el gobierno al que él sirve de consejero actuaba militarmente contra Estados soberanos como Iraq o Yugoslavia (era asesor de Clinton).

Un Estado ideal (imposible) sería aquel que mantuviera un máximo de libertad y un máximo de igualdad, mientras que el Estado más deplorable y degenerado sería aquel que limita al mínimo la libertad y limita al mínimo la igualdad. El caso más aproximado podría ser el que corresponde al nazismo de Hitler, el cual no sólo limitó al mínimo la libertad y la igualdad, al programar el exterminio de una parte especialmente despreciada de la sociedad, y convirtió la fraternidad en una guerra monstruosa. Por esta razón no se puede equiparar el nazismo con la Unión Soviética, puesto que en el socialismo se limita la libertad a costa de la igualdad mientras que en el caso del nazismo estamos ante un claro engendro social degenerado que atesora todas las negaciones hasta el límite, como pudo ocurrir también en la Camboya de Pol Pot.

Engendros políticos parecidos al nazismo se generan siempre muy cerca de los nacionalismos excluyentes y secesionistas que nacen ahora en España. El secesionismo vasco y catalán es racista y xenófobo, lo que quiere decir que practica una des-igualación social activa; en este caso contra aquellos españoles que no son independentistas. Y así como desde la función de planificación económica que le cabe al Estado pueden darse usos corruptos que instrumentalizan la fuerza del Estado para beneficiarse fraudulentamente partidos y distintos grupos de presión o incluso organizaciones criminales; del mismo modo, en el caso del nacionalismo secesionista tenemos la misma situación: estos partidos secesionistas pueden llevar adelante estas políticas degenerativas aprovechando las propias estructuras del Estado; precisamente por esta circunstancia, por el hecho de que cabe esperar que estos partidos secesionistas contribuyan a destruir el Estado es por lo que no sólo no son criticados desde los partidos marxistas, sino que reciben su beneplácito; cosa totalmente absurda, desde luego, porque con ello no sólo contribuyen a crear pequeños Estados más débiles y por tanto menos igualitarios y menos libres y soberanos, sino que su proceso de 
construcción se realiza mediante la negación de los principios más elementales de una ideología socialista: la igualdad política más allá de cualquier determinación biológica o étnica como ideal político.

El nacionalismo secesionista también ejercita una idea de libertad de tipo nacional, moral, no ética. Se apela a la libertad de la colectividad, como si sólo el grupo asociado al nacionalismo secesionista fuera verdaderamente libre, lo que supondrá que aquellos que se apartan de semejante credo serán tomados por sujetos alienados. Interpretar la libertad como propia de una supuesta masa nacional supone a su vez la renuncia a la libertad individual, sustituida por la presión social e ideológica, la manipulación y el control cercano de las actitudes vitales. Cuando decimos que el nacionalismo catalán es excluyente estamos diciendo que se trata de un modelo político que parte de la exclusión de la parte de la sociedad política española que no comparte las mismas ideas, aprovechando que las ideas contrarias sin embargo contemplan un programa de inclusión y preservación de todos los ideales, inclùyendo esos ideales excluyentes y xenófobos que alimentados con tiempo acaban generando una crisis social muy peligrosa.

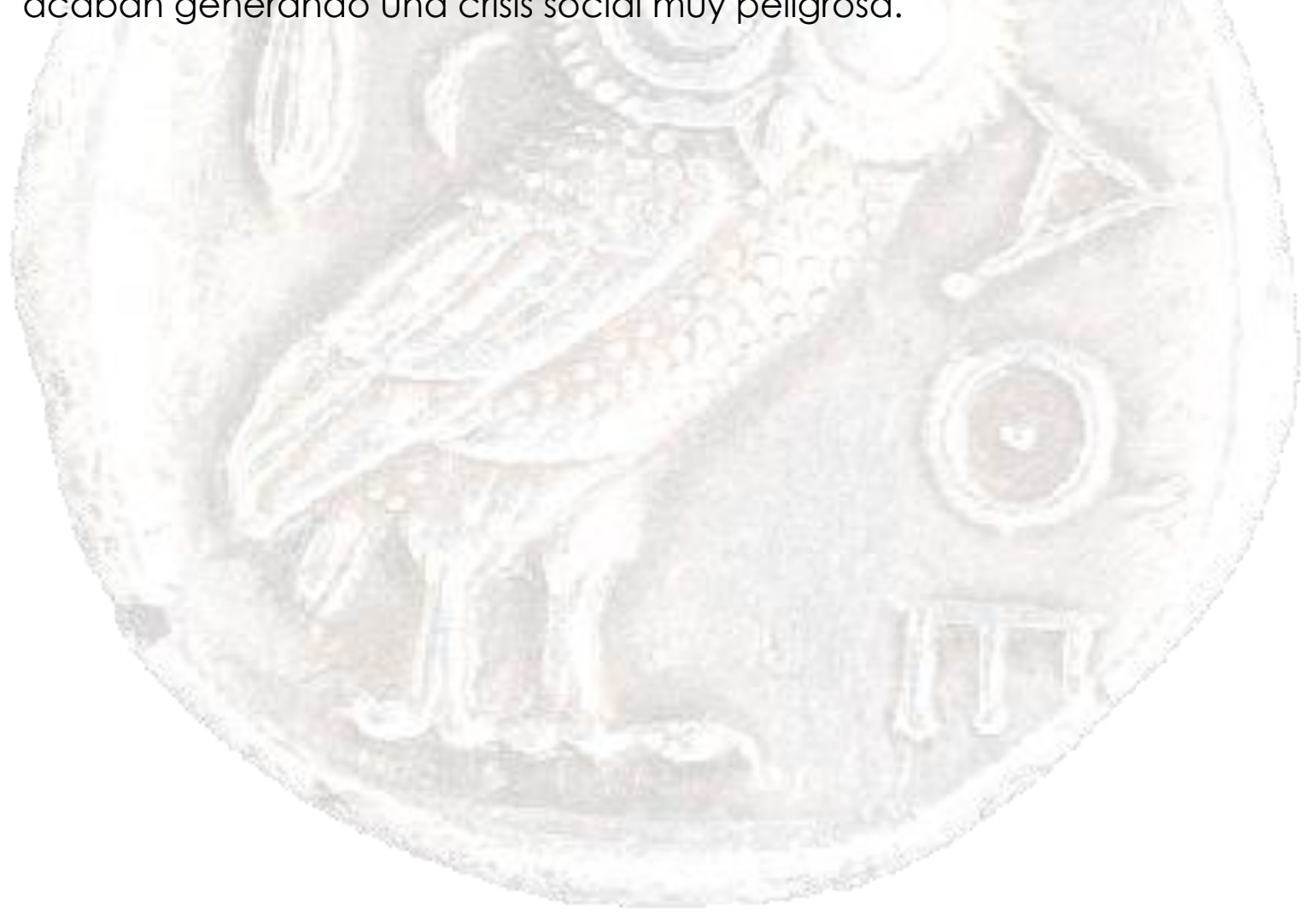




\section{Para una teoría materialista del espacio axiológico: Ética, Moral y Política}

Hemos tomado las tres ideas de libertad, igualdad y fraternidad en términos de máximos y mínimos para analizar las distintas alternativas políticas. Pero desde una perspectiva materialista cada una de estas tres ideas puede entenderse de tres modos distintos. Nos referimos a la perspectiva ética, a la perspectiva moral y a la perspectiva política. Los valores mínimos y máximos de estas ideas deben definirse en términos éticos, morales y políticos para poder establecer diferenciaciones más precisas acerca de las distintas cosmovisiones políticas correspondientes a los diferentes partidos.

El análisis de estas ideas desde la ética, desde la moral y desde la política arroja valores independientes, o disociables, puesto que se trata de dimensiones irreductibles entre sí. Por ello, la composición de las ideas de libertad, igualdad y fraternidad en sus tres dimensiones correspondientes generará una imagen compleja sobre los posibles modelos políticos resultantes. Si suponemos que todas las ideas correspondientes al campo de la axiología se construyen en el espacio tridimensional conformado por las tres dimensiones propuestas (puesto que sus valores aunque son inseparables son disociables entre sí) quizá se podrían estudiar con más detalle los modelos políticos más allá de la distinción de máximos y mínimos que hicimos en el anterior artículo.

El espacio axiológico estaría conformado por tres ejes que serían los siguientes: el eje de la ética, el eje de la moral y el eje de la política. No cabe duda de que dichos ejes tienen una genealogía; cabe suponer que de ellos el primer eje sería el de la moral, mientras que el segundo eje sería el correspondiente a la política, y sólo desde su confrontación nacería el tercer eje, el de la ética. Los tres ejes además permitirían composiciones planas que suponen confrontaciones aunque, por supuesto, esas composiciones binarias se dan siempre mediadas por un tercer eje. Así la confrontación entre ética y moral o entre ética y política o la confrontación entre moral y política. Por tanto la consolidación del espacio axiológico sólo habría tenido lugar muy tarde, particularmente, diríamos, en la democracia ateniense o incluso más adelante, cuando nace la idea del ciudadano universal de los estoicos, porque en rigor la ética se construye de algún modo cuando la figura del ciudadano se extiende al universo.

Todo esto lo propongo, no obstante, tomando como referencia la teoría materialista de Gustavo Bueno sobre ética y moral. Entiende Bueno la ética como el conjunto de disposiciones orientadas a la supervivencia de todos los individuos. La ética toma a los hombres como una clase distributiva, todos son iguales y su delimitación se establece en términos abstractos, aquellos que se perfilan por ejemplo en la Declaración Universal de los Derechos Humanos. Independientemente de sexo, raza, 
religión, origen o clase social, todos los hombres son iguales. La virtud ética se enfrenta a los grupos, pero también se enfrenta al Estado.

Por otro lado, la moral se entiende como el conjunto de disposiciones orientadas a la supervivencia de los grupos, es decir, la moral toma al hombre en la medida en que aparece enclasado y organizado en grupos: clase social, sindicato, horda, banda mafiosa, equipo o sexo, raza, etc. La moral se enfrenta al individuo y puede sacrificarlo en favor del grupo. Pero también se puede enfrentar al Estado y socavarlo, o instrumentalizarlo en su caso para alcanzar sus objetivos. Una multinacional como Vestas, por ejemplo, actúa en su propio interés aprovechando la debilidad de los Estados para sacar de ellos un máximo beneficio y, si llega el caso, como ocurrió en Villadangos del Páramo, en el que no les interesa seguir produciendo allí cierran la empresa y se van. Y no hay más que hablar. Los miles de trabajadores, familias, la comarca entera, que sufrirá las consecuencias es un problema del Estado, no de la empresa. De acuerdo, la empresa puede hacerlo, pero es función del Estado impedirlo, si es fuerte; si es débil, solo puede asumirlo y dejar que los afectados se las arreglen por su cuenta.

Entendemos por política el conjunto de disposiciones orientadas a la supervivencia no ya de grupos divergentes, sino de los propios Estados constituidos por ellos. La política toma al hombre en la medida en que se encuentra determinado por una sociedad política, es decir, lo entiende como ciudadano. Toda sociedad política está compuesta de grupos divergentes en conflicto. El arte de la política consiste precisamente en la gestión y regulación de esos conflictos no desde un punto de vista abstracto o superior, sino desde la perspectiva totalizadora que se puede alcanzar desde alguno de los grupos; pero la organización del Estado supone la subordinación dialéctica de los intereses particulares de los grupos para poder seguir ejerciendo el poder, aunque sólo sea porque así se garantiza la continuidad del poder. Esa subordinación se alcanza cuando ninguno de los grupos divergentes en conflicto es capaz de someter al resto a su dominio, y esa debilidad la va fraguando la soberanía nacional entendida como el conjunto de determinaciones que limitan, canalizan y regulan la continuidad, alternancia y legitimidad del poder y del propio Estado.

Para sobrevivir, el Estado se enfrenta con otros Estados, se alía con otros frente a terceros, etc. Es la dialéctica de Estados. Pero a su vez, el Estado se enfrenta a los grupos, a las multinacionales, a los grupos de presión, mediáticos o de cualquier otro tipo, a las organizaciones de clase, a los partidos políticos; y en esa lucha puede encontrar apoyo en otros colectivos. Pero también se enfrenta al hombre en sentido ético, cuando lo sacrifica en función de intereses bélicos, políticos, etc.

La ética mira al hombre desde una perspectiva universal, por tanto, más allá de toda frontera; la moral también puede mirar al hombre más allá de las fronteras de los Estados, pero no en sentido universal sino particular, 
es decir, en la medida en que los intereses del grupo pueden entrar en conflicto con los del Estado. La política mira al hombre como ciudadano, de manera que comparte con la ética el ideal de la ecualización de todos los ciudadanos dentro del Estado, pero comparte con la moral la idea de que todos los ciudadanos constituyen una unidad política frente a terceros, determinada esencialmente por lo que hemos llamado anteriormente la Soberanía nacional, aunque esté regulada desde el poder de una parte de la sociedad, y esa es su dialéctica.

Así podríamos ahora estudiar las distintas dimensiones que pueden adquirir la libertad, la igualdad y la fraternidad desde la composición articulada de la perspectiva ética, moral y política.

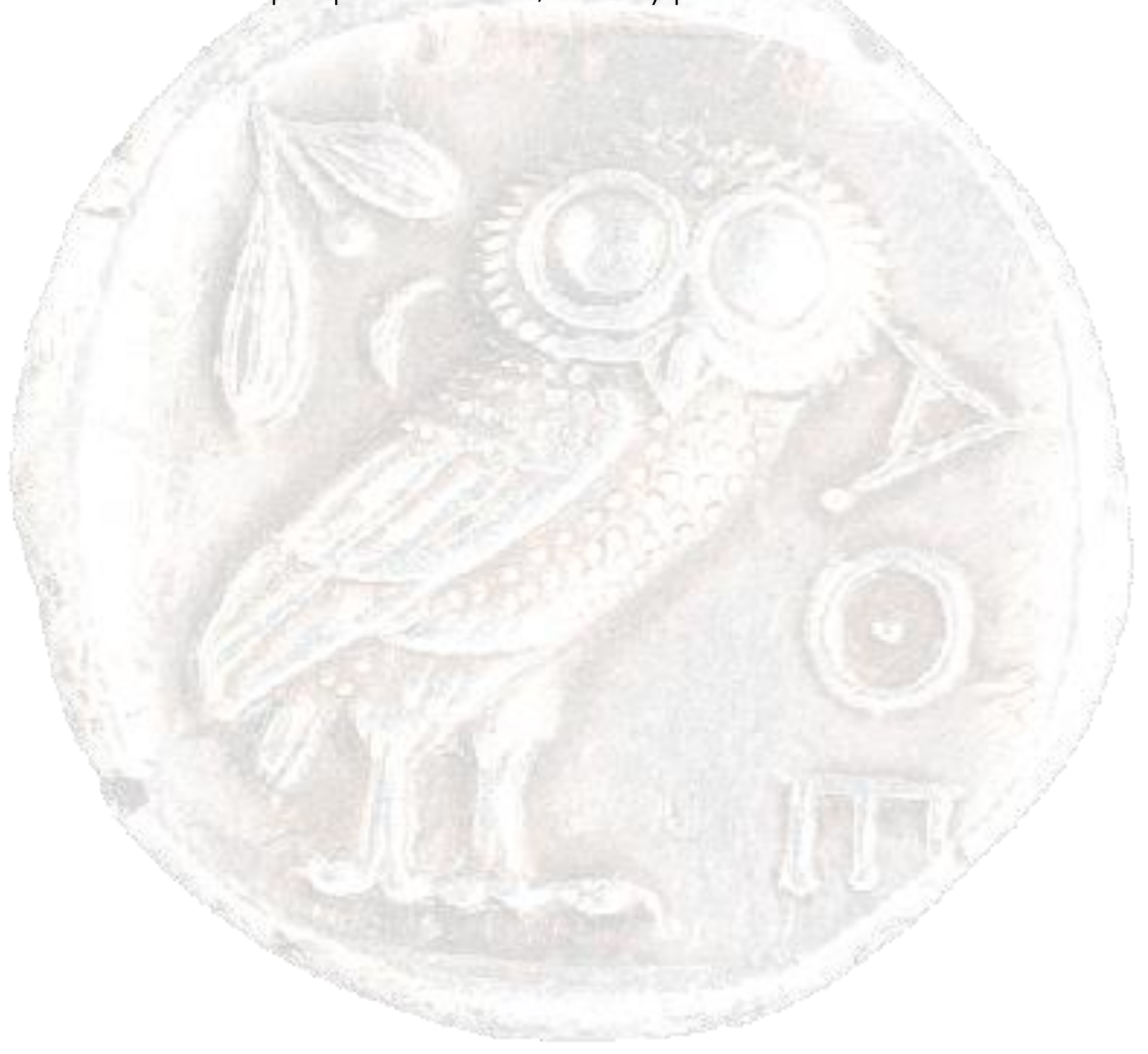




\section{Sobre la Libertad ética, moral y política}

Los partidos políticos suelen apelar a la Libertad como algo absoluto e indiscutible. Ningún partido se atreve a defender hoy lo que Lenin defendió en la Revolución de Octubre, que la libertad tal vez no sea procedente si no va acompañada de un verdadero programa político y de un Estado capaz de proporcionarla. Por ello, más allá de esas defensas abstractas y metafísicas de la liberad, los diferentes partidos políticos deberían determinar de qué tipo de libertad hablan.

La libertad en sentido ético supone entender al individuo como soberano de sus decisiones, frente al Estado, por ejemplo; pero también frente a los diferentes grupos. La libertad puede entenderse también desde un punto de vista moral. Es lo que ocurre cuando un partido defiende una tradición popular, como expresión de un pueblo 0 , en general, cuando se defiende la persistencia de un grupo. La empresa multinacional Vestas apela a la libertad de instalarse en cualquier parte del mundo. La libertad política, por el contrario, se entenderá entonces como la propia soberanía del Estado, la libertad del Estado frente a otros Estados y frente a sus multinacionales, grupos de presión internacional, y grupos de presión dentro del propio Estado que pretenden socavar su fortaleza y la soberanía nacional.

La libertad ética se entiende entonces como la defensa de los fines personales del individuo frente a los planes generales del Estado o de los grupos. La libertad ética puede estar más próxima a las ideologías liberales y neoliberales, también al anarquismo en todas sus vertientes. La moral, como defensa de los programas de los grupos frente a los fines particulares del individuo y frente a los planes generales del Estado, puede encontrarse en la defensa de los intereses de grupos sociales, lobbies, sindicatos, partidos políticos. Esta dimensión de la libertad es la que corresponde más al enfoque político de los partidos que se consideran hoy por hoy en España de izquierda, y en ellos se observa siempre un importante desprecio hacia el individuo particular en la medida en que siempre se toma como sujeto enclasado, o bien enajenado. Recientemente hemos asistido a un discurso de propaganda electoral de un candidato independentista en el que apela a factores basales, como legitimación de su discurso, para luego añadir la defensa de la libertad de Euskalerría entendida precisamente como soberanía nacional propia, frente al resto de los españoles. La igualdad económica entra aquí en conflicto con la libertad política, puesto que según este candidato la soberanía nacional no reside en todo el pueblo español, sino sólo en el País Vasco, que podrá decidir por todos. La libertad en sentido moral inevitablemente entra en contradicción con la libertad en sentido ético, y político. 
Lo que podríamos preguntarnos, respecto a aquellos que pretenden ampararse en una idea ética de libertad, es cómo podría ser ejercida esta libertad individual, por ejemplo, en un clima de tensión ideológica como pudo ser la Alemania de Hitler. Es evidente que sólo la fuerza de algún Estado capaz de doblegar al nazismo podría devolver al individuo particular su libertad individual: así lo decía Vassili Grossman: "Londres callaba, París callaba, toda Europa estaba en silencio mientras los nazis asesinaban industrialmente a sus víctimas. Sólo en Stalingrado rugía la artillería soviética". Y esta es la realidad. En general, sólo el Estado puede garantizar la libertad individual frente a los grupos de presión, oligarquías, asociaciones, partidos, bandas, sindicatos, multinacionales, etc. El Estado soberano es aquel que es capaz de defender al individuo particular frente a la presión de los grupos, y en esta dialéctica se han dado infinidad de situaciones históricas curiosas, desde la conquista de México por Hernán Cortés, hasta la Guerra de los Comuneros, etc. La libertad ética no puede ejercitarse sin una fuerza capaz de hacerla efectiva, y esa debe ser la función que cumple el Estado, de modo que sólo desde la libertad política es posible la libertad ética.

La libertad política se basa en la soberanía nacional, por tanto depende de la fortaleza del Estado. Por ello, sólo podemos hablar de ciudadanos libres cuando el Estado del que son ciudadanos es soberano frente a terceros: frente a otros países en la dialéctica de Estados; y sobre todo frente a otros grupos, multinacionales, lobbies, organizaciones criminales, partidos políticos, etc. Hay que tener en cuenta que la libertad de un Estado no sólo viene socavada por la presencia de grupos de presión que actúen al servicio de intereses internacionales, o de otras naciones, o bien de organizaciones supranacionales con las que habrá que lidiar lo mejor que se pueda, como por ejemplo la OTAN, etc. Pero desde luego, la libertad del ciudadano en el Estado en tanto que depende de la fortaleza del Estado, también depende de su articulación interna, y por tanto de su cohesión.

La presencia de grupos disidentes, de tendencias divergentes 0 secesionistas, como en el caso de España, contribuye de modo nefasto a reducir nuestra libertad, a dejarnos al albur de decisiones que otros países pueden tomar frente a nosotros, a la propia posibilidad real de que esos partidos secesionistas estén siendo apoyados por terceros países. Es evidente que la dialéctica de Estados se basa en unjuego determinado por las diferentes fortalezas esgrimidas por cada Estado. No en vano nuestro presidente Juan Negrín denunció a los secesionistas traidores a la República en la Guerra Civil, algo que hoy se olvida por todos aquellos que van de la mano celebrando el aniversario de la República con banderas no ya solamente republicanas, sino decididamente secesionistas, bajo las cuales determinados partidos políticos traicionaron siempre que pudieron a la República. ¿ Cómo ejercer la libertad individual en un clima de represión ideológica ambiental fuerte, como el que puede darse hoy por hoy en Cataluña? Hemos visto en estos días a Inés 
Arrimadas intentando dar un mitin en Vic acosada por una banda de fanáticos separatistas. Aquí se pone de manifiesto que sólo un Estado fuerte es capaz de frenar la presencia nefasta de estos grupos de radicales fanatizados, claramente enajenados porque no comprenden ni lo que hacen, ni las razones por las cuales pueden permitirse el lujo de comportarse de un modo tan reaccionario y nefasto. Sin la fuerza del Estado es imposible. Aunque también es cierto que el Estado puede ser un agente de disolución de la libertad individual, sin duda, pero no el Estado democrático, tal y como lo hemos establecido, ese que permite que esos fanáticos puedan seguir viviendo del Estado a pesar de todo.

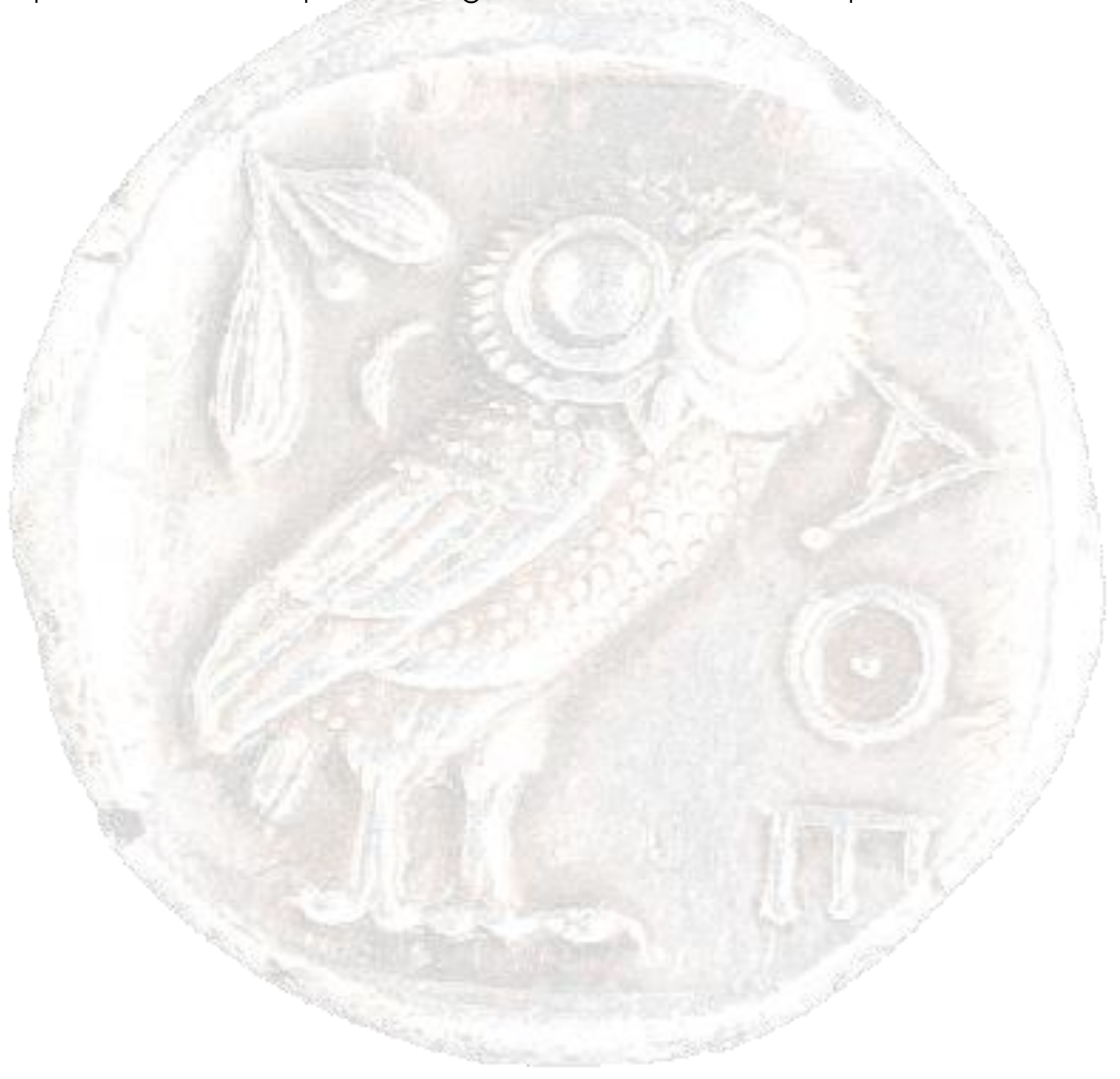




\section{Sobre la Igualdad ética, moral y política}

Analicemos ahora, desde la perspectiva Ética, Moral y Política la idea de igualdad. La igualdad puede entenderse también desde la perspectiva del individuo particular: "todos somos iguales ante la ley"; pero también se puede entender desde la perspectiva moral: "los catalanes tienen derecho a decidir". Desde la perspectiva política la igualdad consiste sin duda en la redistribución de la riqueza, que es la función esencial del Estado para su propia subsistencia. Por tanto, la única función propia de la igualdad es la que corresponde con la perspectiva ética. De hecho, la igualdad basal no puede defenderse desde la perspectiva moral, porque en ella se trata de la defensa de la igualdad entre los miembros del grupo, frente a otros grupos, lo que únicamente puede contribuir a la desigualdad. Es imposible la igualdad moral. La igualdad política es la realización efectiva positiva del ideal de la igualdad ética, por tanto, siempre se da en conflicto con los grupos divergentes; pudo muy bien ser de otro modo, cuando, por ejemplo, no se reconocía a diversos colectivos una responsabilidad económica, pero esto hoy en día resulta absolutamente imposible.

Por ello, cualquier apelación a la igualdad en términos morales es incongruente. Cuando un político grita por la soberanía nacional del País Vasco y trata de convencer a los españoles de que de ese modo habrá más igualdad económica entre todos, está diciendo que la igualdad económica entre todos los españoles depende de la desigualdad política entre los españoles, y en rigor, depende de que la soberanía nacional española esté en manos de su partido en el País Vasco. Lamentablemente este es el argumento general de las izquierdas en España, cuando se razona sobre la idea de la España plurinacional, como si existieran, en efecto, diferentes naciones políticas. Se parte de la idea de que la justicia social económica depende de una profunda injusticia social política, basada en los privilegios soberanos.

La igualdad política se aproxima a la igualdad ética, en la medida en que debe partir del principio de que todos los ciudadanos son tomados como iguales, porque esta idea de la igualad no tiene parámetros. Al contrario, la igualdad de que se parte en el Estado no es una igualdad abstracta, como la que desde la ética se establece en la Declaración Universal de los Derechos Humanos, sino la igualdad resultante de la composición y redistribución de la riqueza que dentro del Estado cabe gestionar en uso de la soberanía nacional por parte de todos los ciudadanos. Así esa igualdad es una igualdad calculable, operable, gestionable y delimitable a través de la Hacienda pública y los impuestos de redistribución de la riqueza. Por tanto, es una igualdad basada en los parámetros determinados por la riqueza del Estado. Pero esta riqueza del Estado sólo es redistribuible en igualdad por el principio de que la soberanía nacional es asunto de todos y cada uno de los ciudadanos. 
No se entiende cómo favorece la igualdad el hecho de que la soberanía de la nación quede en manos de una región particular y no porque este los partidos que defienden la autodeterminación de su región tengan malas intenciones o estén ocultando planes más perversos, no se trata de si se actúa con premeditación o si verdaderamente se propone de buena fe. Admitamos que se dice de buena fe, si así fuera se entiende que el resto de los españoles somos sujetos ajenos a la soberanía y por tanto se nos está tomando como seres enajenados de toda soberanía. Pero la soberanía debe defenderse incluso contra estas buenas intenciones, porque sólo la soberanía nacional puede garantizar que al margen de la buena voluntad de seres superiores, los españoles, en este caso, puedan disponer legítimamente de su riqueza real. Otra cosa es que no te guste lo que la gente suele votar, eso es otro asunto, pero así es la Democracia.

\section{Sobre la Fraternidad ética, moral y política}

En el caso de la Fraternidad, es evidente que cabe la fraternidad ética. De hecho, sobre esta fraternidad ética se conforman todos los discursos de acogida de inmigrantes legales e ilegales llegados a las costas españolas desde diversos puntos geográficos. Es evidente que la ética es ante todo fraterna y no hay límite para el cuidado y la defensa de la vida de cualquier ser humano por serlo, independientemente de la raza, la religión, el sexo, etc. La fraternidad también puede entenderse desde un punto de vista moral. Y tiene mucho sentido, porque hay grupos sociales que trascienden las fronteras nacionales. Por ejemplo, grupos religiosos. Pueden existir programas de acogida fraterna para aquellos pertenecientes a la misma religión o a la misma etnia. Así, por ejemplo, algunas regiones priorizan programas de acogida de inmigrantes de una determinada religión, lo que significa que se está utilizando un enfoque moral de la fraternidad, quizá bajo la apariencia de un ejercicio de fraternidad ético. Sin embargo, esos planes pueden obedecer a determinadas intenciones políticas. Y es que tampoco resulta fácil descontextualizar los elementos de cohesión culturales que existen entre las naciones.

Así pues, los programas políticos relacionados con la fraternidad mantienen una importante dialéctica entre el enfoque ético y moral. Por otro lado, excuso decir lo que puede deducirse del enfoque moral en relación con la fraternidad cuando se trata de grupos organizados, incluso grupos delincuentes, que actúan a través de las fronteras, pero también, por ejemplo, la acción de multinacionales, proyectos filantrópicos como puede ser el derivado de las reuniones del Club Bilderberg, o las insidiosas intromisiones denunciadas contra George Soros, por ejemplo. En este caso, se muestra que la presencia de grupos 
trasnacionales actúa directamente debilitando y poniendo en peligro la eutaxía del Estado.

La fortaleza del Estado debería dirigirse y sostenerse, en este sentido, por programas orientados no tanto a la recepción de masas de inmigrantes, cosa que resulta inevitable y de pura humanidad, sino a la intervención del Estado en aquellos países que por debilidad estructural pierden población de modo preocupante. Deberían procurarse políticas de fortalecimiento para dichos países. Es decir, la labor de los estados es contribuir a elevar a la condición de estado soberano a aquellos territorios que por diversas razones no han alcanzado el equilibrio de fuerzas suficiente para decantar una soberanía nacional común. Tarea difícil y compleja que siempre está en discusión, como podemos comprobar en España actualmente. Y resulta curioso que un partido entendido como de derechas, como el PP, ofrezca un proyecto llamado Plan Marshall para África; una idea digna de una verdadera política de izquierdas con respecto a la inmigración. Al menos para conseguir que quien desee abandonar su país no lo haga por necesidad, sino en el ejercicio de su libertad individual.

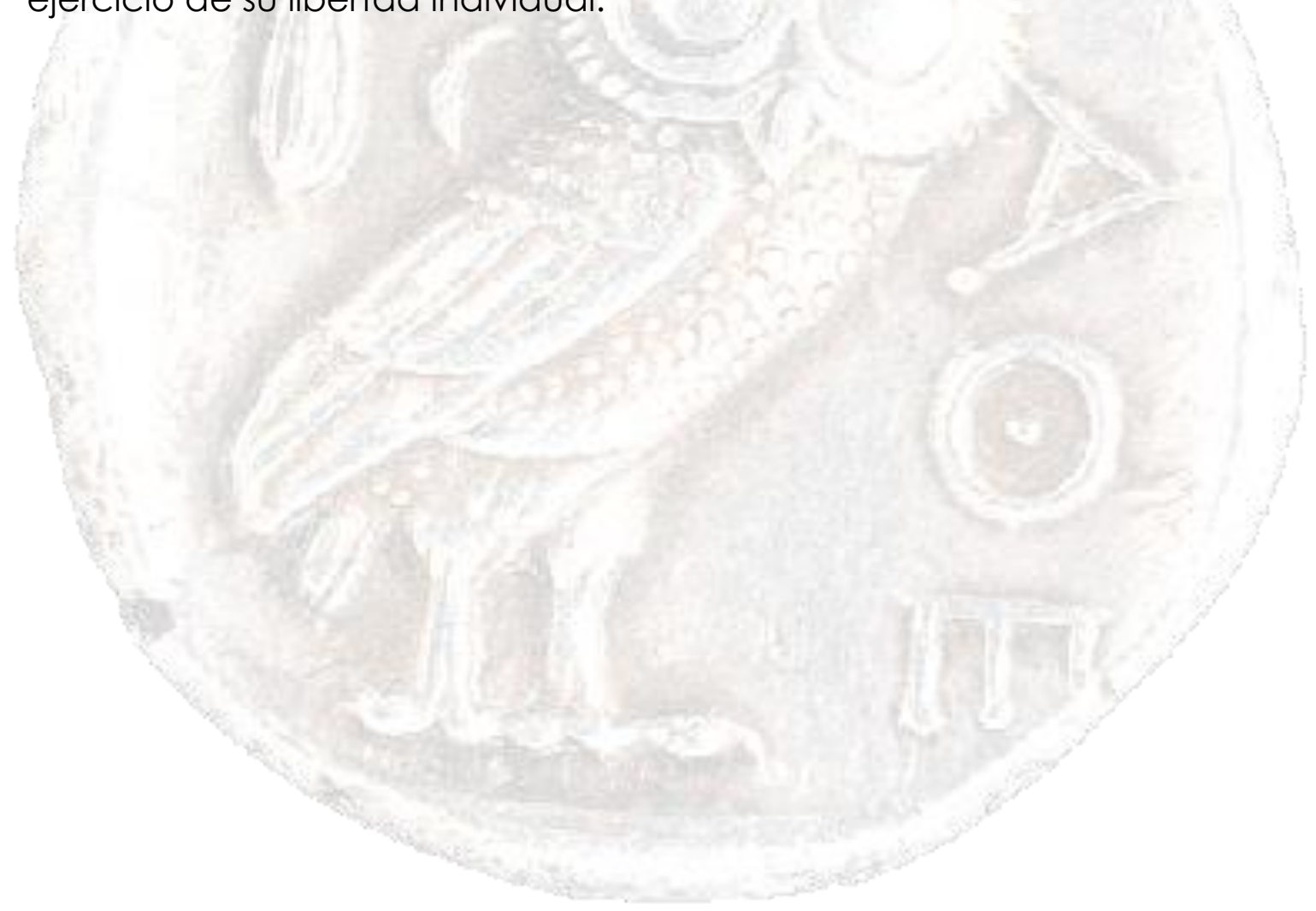

